\title{
THE ROLE OF MUSIC IN PSYCHOLOGICAL AND EMOTIONAL DEVELOPMENT
}

\author{
Shveata Mishra ${ }^{1}, \&$ Ina Shastri ${ }^{2}$ \\ ${ }^{1}$ Music Therapist, Music Psychologist \& Research Supervisor, Banasthali Vidyapith, Rajasthan (India) \\ ${ }^{2}$ Head of Department of Music, Banasthali Vidyapith (University), Rajasthan (India)
}

\begin{abstract}
It is widely believed that a truly "whole" person is one whose intellectual and emotional responses are normally developed; yet our patterns in education tend to stress the intellectual and ignore the emotional. $\mathrm{Te}$ arts, because of their emotional demands, make for. stronger bond between persons who can share in the art experience. This is especially so of music which has a long been termed the universal tongue. It is a form of communication in which every human being can participate. Many studies have shown that it is not by accident that we find minimal behaviour problems among the students who are involved with music study. It is now believed that the child who becomes involved in expressing himself/herself through the media of music takes on new dimensions in his or her psychological, behavioural and sociological relationships. It is this paper, we shall draw upon the experiences of music educationists from various countries, and as a consequence, it is reaffirmed that for a holistic and balanced development of students personalities music study should be mandatory in school curricula.
\end{abstract}

Keywords: Art, communication, emotional development, music, musical development, personality, psychological development, psychology of music.

\section{Introduction}

A programme of music rests on the assumption that if members of society are to achieve a sense of dignity and worth they must have access to a variety of forms of cultural expression. Psychological appraisal of the field of music emphasise the importance of artistic expression and validate its importance for the development of the whole human being. A truly whole person is one whose intellectual and emotional responses are normally developed. It is the duty of the educators, therefore to develop the entire range of human capabilities. Yet, our patterns in education tend to stress the intellectual and ignore the emotional.

The arts because of their emotional demands, make for a stronger bond between persons who can share in the art experience. This is specially so of music which has long been termed the universal tongue. It is a form of communication in which every human being can participate. It follows that music educators have the responsibility to make their students capable of sharing to the highest degree in this art form, and music should enter the educational scene.

\section{Music and psychological and emotional development}

Many studies have shown that it is not by accident that we find minimal behaviour problems among the students who are involved with music study. It is now believed that the child who becomes involved in expressing himself through the media of music takes on a new dimension in his or her behavioural and sociological relationships. It would appear that the creativity which is latent in the human being brings out a deeper sense of responsibility and therefore a better introspective understanding of the student.

The re emphasise the importance of music in the all around development we shall draw upon the experiences of various music educators in different social, political and economical contexts. 


\section{Experiences from across the globe}

In this section we draw upon the experiences of various music educators from countries as diverse as Soviet Union, Hungary, Germany, Canada, Britain, USA.

Soviet Union - About 90 years ago when asked by a critic what he thought about the future of music education in Russia, P.I. Tchaikovsky said: Schools must be started in our capital cities and towns. The purpose of these schools would be to train young people for the conservatoire. Choir singing should spread and become a fixture in all the primary schools of our land. To the next question - "Can all this be accomplished by private initiative alone? - Tachaikovsky replied: Hardly. It would be the greatest blessing for Russian art if the government assumed patronage over all its branches; only the government has the means, strength and power needed for this great undertaking.

Tchaikovsky's wish came true only after the Great October Socialist Revolution. And not at all because the young Soviet Government had more means, strength and power than the house of Romans of which had pompously celebrated its tercentenary shortly before the revolution. On the contrary we know what tremendous hardships confronted the young Soviet Republic from the first day of its existence.

In 1918 when Soviet Union was in the stranglehold of foreign intervention, counter revolution, hunger, cold economic dislocation and epidemics when the country's very life seemed to hang by a hair, the Soviet Government adopted a number of decrees in full measure to professional and mass music education.

With the very first decree on general schools, music and the fine arts were included in the curriculum as compulsory subjects for all school children from the first from up. The task of providing all pupils with an aesthetic education was made the responsibility of schools supplying a general education.

there can be no doubt that this task would have been accomplished by now, were it not for the great losses inflicted upon in all fields of life by the last war. Alas, these losses were too heavy, and after the war much has to be begun from scratch. In the Soviet Union today there are close to a quarter of a million secondary schools and providing them with all the necessary equipment and most important of all with able and gifted teachers, is indeed a formidable task.

But these difficulties differ essentially from the difficulties of those countries where the responsibility for providing a general musical education has not yet been assumed by the state. Enormous efforts are already directed towards implementing with the utmost efficiency the very clear cut state programme.

\subsection{Hungary}

Let us remember the eminent composer and teacher, Zoltan Kodaly whose chosen path deserves our deep respect. All his life he fought for a general music education for the Hungarian people, but it was only after Hungary was set free in 1945 that he was able to implement his educational ideas.

Let us take a good look at the position of music education in some of the greatest countries of the world whose governments have the means strength and power but do not express the interests of the people. Their teachers are still only dreaming of general music education for all.

So there you are- all the evidence goes to show that this is not the matter of means strength and power. For a government to provide education including music education for the entire population it must be a government of the people embodying, promoting and wholeheartedly serving the interests of the people.

\subsection{Germany}

The aims and objective of music education in the schools in Federal Republic of Germany are as follows:

1. Show the way to the understanding of music for each child

2. Prepare young people to find their bearings in the world of music that will surround them in later life

3. Introduce music to the pupils as an art in its own right

4. Be the basis of a general musical culture i.e. one that embraces the whole population

\section{GDR}

Though the country lost its existence due to German reunification the experiences of the erstwhile East Germany are noteworthy as it highlights the significance of music as perceived in the socialistic thought.

In a socialist society, steadily raising the cultural level of the people as a whole is one of the most important components of the development of the society. The character and pace of social progress, whether it is in terms of the technological revolution or of the people's notions, depends to a considerable degree on 
the way their process; the one decisive factor is the future development of our national culture, which a now really be said to belong to the people as a whole.

This article of the constitution is devoted to defining the character of the personality in a socialist society. The main trait of this character is a deeply humanist conception of man as the active, creative maker of his life, man who can overcome the constantly increasing demands on him of the scientific technological revolution combined with the demands of the socialist cultural revolution and at the same time be able to affirm himself as a self conscious personality. This kind of man is a justification of the fundamental claim of our socialist society to educate the personality. This view of man is relevant not only in terms of educating the individual today, but also in terms of the characteristics and qualities common and innate to all men, which will be just as much part of human being of the third millennium as of our contemporaries. And so, when we speak of the problems of education, the most important thing for us is to aim for all man's infinite capabilities: the development of the individual in its totality and universality (Karl Marx).

The educational system of GDR was designed precisely to this end. It aims at the knowledge of the mother tongue, of mathematics, of the natural and social sciences, technology, of foreign languages, physical training and the different arts. Spiritual, technical, physical and aesthetic development are combined into one streamlined system.

This is why we do not today regard instilling an aesthetic sense into the growing generation as an educational luxury which we can allow ourselves only when we have seen other, more basic, educational needs. On the contrary, if this irreplaceable sphere of aesthetic education were neglected, we could no longer speak of our educational system as fostering all round development. We take as our starting position the view that in the years to come no spiritual moral or ethical teaching could exist without corresponding aesthetic instruction and vice versa.

The task of art is of course to develop our awareness of beauty and stimulate the positive sides of the man's character and his creative powers. That is why within the educational system of the GDR music education is closely connected with aesthetic education. A formative emotional awareness of the strength of music can be an exceptionally important factor in the making of an individual, for it is music that brings out in man a wide range of feelings and thoughts and lends wings to his mind.

The moulding of the individual cannot be left to simplify a rational education. It must also contribute to the development of human emotions and develop a breadth of feelings as the expression of, and a creative element of man's practical and psychological attitudes, and it must bring out an equilibrium between his feelings, thoughts and actions. Thanks to the fact that it acts in a specifically emotional manner , music is the art which really can create a oneness of human awareness and human behaviour. Lenin shows us the scale of this problem when he says that without human feelings man would never have sought truth and that there can never be such search in the future either. And so it is in music education that great stress must be laid on the activating of man's emotional strength and the awakening of his intellectual and moral resources.

\subsection{Canada}

G. Little spoke of the reorganisation of the music education system that was undertaken in accordance with recommendations of the commission of inquiry into the Teaching of the Arts in Quebec, headed by Marcel Rioux. The Commission's aim was to study the state of affairs in art education and to work out proposals for its improvement. G Little said that under conditions of the new open culture education as a whole is a system of mutual exchanges established between teacher and pupil with the aim of developing and forming the pupil and art education is a general social phenomenon a component part of general education not a luxury or something extraneous designed for the elite.

Art is more a subject of character development than of education. Art education is fundamental personality development and not simply the transmission of certain techniques. The aim of this education is to promote the development of creative abilities, emotionality of perception, and social consciousness through aesthetic experience. Thus, there arises the need for a two sided orientation in art education the pre professional and the non professional that is it is both a question of teaching art (teaching specific techniques and conveying knowledge) and of teaching through art, that is of developing the human personality with the help of art. The isolation of the arts disciplines from the rest of education is being broken down. In particular music is ceasing to be a special separate world.

To avoid replacing one rigid system with another and to ensure open pedagogy as much as possible programme plans instead of programme catalogue are proposed. It is recommended that these programmes be reviewed every five years. G. Little then spoke of the organisation of art and in particular music education in Quebec according to the principles worked out in the report of M. Rioux's Commission.

All children receive music education beginning from the preschool period until the end of the first cycle of secondary school that is from 5 to 14 years old. At the preschool age at least half of the lessons scheduled are devoted to various kinds of art activity: rhythmics, theatricalise games, imitative arts and 
music. In primary grades no less than seven hours a week are devoted to art education, including half an hour a day to music. A teacher that has no special training in this area is aided greatly by records and radio and television programmes organised by the Ministry of Education's technical teaching aids services.

In secondary school the following art forms are offered: music, fine arts, theatre, photography and as far as possible radio television and the cinema, dancing and rhythmics. At the beginning of this stage music studies are compulsory (three hours a week) Later they are elective: The pupil may choose from among the forms of art activity he had been previously engaged in and go through a higher level course offering pre professional training. On the college and university level, the weekly programme of every student must include one or another art discipline.

The commission's report also provides for teacher training and upgrading: every teacher no matter what field he specialises in, receives a basic art education. On the other hand, teachers specialising in art must have a fundamental knowledge of other disciplines.

Thanks to an open and flexible system, the report says that art education will embrace all children without exception. Children and youth will acquire more than knowledge and experience in the field of art: art will help them to develop their personality, to take their place in today's world and take part in building the future.

In the case of any radical change, obstacles inevitably arise, but despite such obstacles, the reform is being successfully implemented through the efforts of many accomplished and dedicated music teachers. We are moving towards the future along the irreversible path of progress; this path is inevitably leading us to an open society in which the information media are turning the entire human experience, including music into a universal social phenomenon.

\subsection{Britain}

D. Hamilton, based on his own experience as a music teacher in using contemporary music, points out that he makes considerable use of contemporary music in teaching even the youngest and most elementary pupils while most of his fellow teachers insist that children like nothing better than a decent melody and a tune they can sing. He thinks that it would be almost impossible to explain to such people that his pupils old and young do not suffer pain from continual discrepancies that their appreciation of a melody, is frequently heightened not inhibited by harmony unknown to Hummel and Czerny; that regular bar lines are perhaps not a prerequisite of rhythmic well being.

D. Hamilton is sure that the young will accept modern music if it is seen to be really accepted by their teachers. He emphasises that it is no use to merely resent a child with an occasional piece in contemporary style, one has to be enthused about its structure, its harmony, it's economy not only its novelty and to lead a novice into another branch of music. He feels it is necessary to define the term modern music and he underlines that it cannot mean any music written within the last two decades He is of the opinion that modern music can include music written since about 1920 and which employs harmony rhythm or structure which differ radically from that used in the nineteenth century. There is modern romantic music modern sophisticated music modern uncompromising music. There is above all a wealth of small pieces based on folk song or folk dance in which simple melodies are made exquisite by the addition of a counter melody suggesting remote harmony or are made vital by expected often syncopated rhythms.

Speaking about music for beginners which was written during this century by composers of great ability such as Bartok, Bennett Ibert Kabalevsky, Lutoslawaki, Prokofiev and many others, D. Hamilton stresses that the music is not only easy but it is of high quality, and it impresses beginners as real music not merely as learners music.

Many teachers wrongly introduce their pupils to modern music when they are no longer beginners, and have acquired a little knowledge of traditional harmony. At the age of 12 or 13 and after playing for 3 or 4 years children begin to feel that they know what music is all about and are often resentful towards a new kind of music. Antagonism is almost certain to be engendered towards composers who not only break all the rules, but who seem to make up a new set of rules for every piece and this antagonism may last for a lifetime.

From his point of view a great advantage is that young people who are reared in 20th century music tend to be less dogmatic in their preferences, their ability to criticise objectively rarely being impaired by the strangeness of new sounds. Meanwhile those who are brought up entirely on music based on the major/minor key system have great difficulty in appreciating the vast amount of music written before that system appeared or after it had been superseded.

\section{The Indian experiences}

The experiences about the power of music from the world over continue to baffle. Its influence often is far beyond the domain of emotions. A recent study has shown that elderly people with dementia 
answered. questions about their personal history better when there was music playing in the background then when it was quiet. Whether the music was familiar or new didn't seem to matter. The music probably aroused the participant and helped them focus. Music is increasingly being used for treatment as it has a simultaneous calming and energising effect. Our system of Mathematics teaching at elementary school level through rhymes has attracted the attention of the entire world for its effectiveness.

\section{Conclusion}

Despite all this, a review of the courses of study, which a student of music takes for general academic training, shows that now the subject of music is peripheral. It doesn't enjoy the same level of intensive teaching as the other courses. Even the best of educators do not regard the study of music as a vital and integral part of a student's development. It is as if they are bent in developing all the intellectual resources of the student and are not cognisant of the crippling emotional limitations of an education that is devoid of music. Besides youth must be prepared to have identification with his fellows on a global basis.

$\mathrm{He} / \mathrm{she}$ must find areas in human relations that will associate him/her with peoples of all countries. Notwithstanding the varied culture of the world, people do find a common denominator through the expression of music. Music can prepare youth for this kind of reciprocal understanding.

To achieve this is not an easy task. It requires dedicated mature musicians to evolve a musical environment where the student expands in a positive manner. It requires a course of study in which the student is an active participant in musical expression. Passive techniques have little impact. Sitting and listening to music must not become the basic technique for music studies. The excitement of doing the reward of an accomplished performance and the equally important reward of listening with a depth of understanding.

The foremost factor is the role of parental influence because it can spell success or failure in a student's music education. Too often the parents dispose of what they believe is their parental obligation by allowing the child to study music but then completely abrogate their responsibilities by permitting the child discontinue studying music if she is so inclined. In good measure the parental attitude is a reflection of their own limited understanding of music and it's influence on a child's development.

It is important to seek techniques whereby a child's affiliation with music is serious in nature profound in depth and dedicated to make the child a total human being. By making music study an extracurricular activity is a denial of serious educational principals that music study should be mandatory in school curricula, that the student's school day should include time for instrumental and theoretical training in music.

\section{References}

Mishra, S. (2019). Musically Inclined Personality and Behaviour - The Unknown Connection. Chennai, Notion Press, 2019.

Misra, S. and Shastri, I. (2014). Paper published in International Journal of Research and Scientific Innovation (IJRSI) titled: Empirical Study: Impact of Music on Personality and Behaviour of Children: ISSN: 2321-2705.

Misra, S. and Shastri, I. (2014). Paper published in Asian Journal of Multidisciplinary Studies titled: The Role of Music in Psychological and Emotional Development: ISSN: $2321-8819$

Misra, S. and Shastri, I. (2014). Paper published in Journal of International Academic Research for Multidisciplinary (JIARM) titled: Reflection of Music on the Personality from Infancy to Childhood: ISSN: $2320-5083$

Misra, S. and Shastri, I. (2016). Perceptual Experience and Auditory Inclination of Music According to the Sexuality. Psychology and Behavioral Sciences. Vol. 5, No., 2016, pp-7-11. Doi: 10.11648/j.pbs.20160501.12 